\title{
The Influence of Wobble Board on Spatial Learning and Navigation: Sex Differences in Learning Performance
}

\author{
Burak Erdeniz \& Merve Bulut \\ İzmir University of Economics \\ Department of Psychology
}

\begin{abstract}
In order to determine how postural control affects spatial memory performance, the present study looked at the interaction between postural control on a wobble board and performance in a concurrent spatial navigation task (virtual Morris water maze) in 68 participants. Participants in dual task condition navigated the virtual maze on a wobble board, while participants in single task condition navigated in the normal standing way. Postural sway errors on wobble board, path length and duration to find platform were measured during the experiment. The main effect of the condition showed that participants in the dual task condition took longer paths to find the hidden platform, and were slower compared to participants in the single task condition. In terms of sex differences, the results showed that male participants found the hidden platform faster and used shorter paths than females in both conditions.
\end{abstract}

Keywords: Postural control, balance board, spatial memory, maze navigation, wobble board 


\section{Introduction}

Spatial memory concerns the ability to navigate and store spatial features of the environment to create a cognitive map for navigation (McNaughton et al., 2006). Previous studies showed that spatial memory depends not only on the visual system, but also on vestibular and somato-sensory senses (Potegal et al., 1977; Etienne, 1985; Mittelstaedt \& Mittelstaedt, 1980; Horn et al., 1981; Potegal, 1982; Miller et al., 1983; Berthoz \& ViaudDelmon, 1999; Etienne \& Jeffery, 2004; Pfeiffer, Serion \& Blanke, 2014). Over the past two decades, one of the most important research questions in spatial memory is to determine the degree to which vestibular and somato-sensory senses are used for encoding the spatial information into memory (Kerr, et.al., 1985; Wiener \& Berthoz, 1993; Berthoz, 1996; McNaughton et al., 1996; Etienne \& Jeffery, 2004; Lackner \& DiZio, 2005; Bigelow \& Agraval, 2015). One suggestion is that proprioceptive and vestibular senses provide information about both the speed and direction of the movement used for updating the location of the body (Loomis et.al., 1999). Overall, these findings suggest that spatial memory may rely on a common neural mechanism shared by the postural control and balance mechanisms (Potegal, 1982; Rieser, Guth, \& Hill, 1986; Waller, Loomis, \& Steck; 2003). In fact, direct evidence comes from previous studies with human participants, which showed that training on various balance tasks significantly increases performance in spatial memory (Rogge et al., 2017), and, in professional dancers and slackliners, leads to anatomical changes in cortical and subcortical regions (Hüfner et al., 2011; Hanggi et al. 2011; Hummel et al., 2014).

The relationship between spatial memory and balance has generally been tested by the dual task interference paradigms (Abernethy, 1988), which measure performance changes in dual-task (postural-cognitive task setting) (Kerr, et.al., 1985; Swan et al., 2004; Fraizer and Mitra; 2008). The capacity-sharing models suggests that if interference occurs between the performances in two tasks, these processes may compete for shared processing resources. 
Intriguingly, dual task studies sometimes yielded seemingly conflicting results and conclusions (Kerr et al., 1985; Maylor \& Wing, 1996; Shumway-Cook et al., 1997 Andersson, Yardley, \& Luxon, 1998; Shumway-Cook \&, Woollacott, 2000; Maylor, Allison, \& Wing, 2001; Swan et al., 2004; Silsupadol et al., 2006). As an example of this conflict, Kerr et al. (1985) showed that while maintaining a difficult standing balance position, the balance task disrupted spatial but not non-spatial memory performance; in contrast, Gale and colleagues (1990) found that the group of subjects who walked a path learnt it better than those who watched a video presentation of it (see also Swan et al., 2004). It remains likely that the proprioceptive and vestibular information during active standing can either improve or impair spatial learning, depending on the compatibility between two tasks (Fraizer \& Mitra; 2008), which can be affected by whether the participants are standing or walking, or whether on a stable or dynamic surface (Waller, Loomis, \& Haun, 2004).

Finally, questions regarding sex differences in spatial cognition, especially navigation, have been well researched, but despite the large number of studies focusing on the differences in performance during a dual task, the spatial learning paradigm remains unclear. A number of previous studies indicate that males show better performance on a diverse set of spatial tests (for a review see Coluccia, \& Louse, 2004). For example, Galea \& Kimura (1993) used an experiment involving tracing a novel route through a town to identify differences between males and females. Performance results showed that males made fewer errors and required fewer trials to learn the novel route. Additional support is provided by Moffat et al. (1998), who investigated sex differences in spatial ability using computer generated mazes, finding that across trials, males solved the mazes significantly faster than females, and made significantly fewer errors (see also Persson et.al. 2013). However, it is important to note that, although many previous studies suggest male superiority in spatial memory, some studies found no sex differences (Wilson, Foreman, \& Tlauka 1997; Rossano, \& Moak, 1998; Darken, \& Sibert 
1996), and the source of any differences is still not well understood.

In order to determine how postural control affects navigation performance, the present study investigated the interaction between postural control on a wobble board and performance in a concurrent spatial location memory task (virtual Morris water maze). As noted earlier, it is still unclear whether the balance task on a wobble board will disrupt or improve spatial memory performance. Based on the capacity sharing models and bottle-neck accounts of dual task paradigms, it is plausible that information processing in spatial learning and of sensorimotor responses is impaired by incompatibility between the motor needs for maintaining balance and the motor needs for the spatial learning task (Tombu \& Jolicœur, 2003; Marois \& Ivanoff, 2005). If this is indeed the case, we expect that uncontrollable rotations of the wobble board and sway performance errors while maintaining balance would impair performance in the spatial memory task. To our knowledge, this is the first study to test this hypothesis.

Secondly, it is important to understand how sex differences differentially contribute to dual task performance, and whether sex advantage in one task can compensate performance in the other. Based on the evidence summarized above, we hypothesized that males would show better performance in the spatial memory task, but it is plausible that males and females might have different task priorities (spatial memory vs balance), and show differential superiority in different tasks.

\section{Procedure}

In order to identify any fundamental differences in balance performance prior to the experiment, all participants completed Berg Balance Scale (Berg et.al., 1989) and an independent experimenter rated performances. The Berg Balance Scale (BBS), developed to measure balance among older people with impaired balance function, is a valid instrument used for evaluation of the effectiveness of interventions and for quantitative descriptions of function 
in clinical practice and research. There are 14 items each scored between 0 and 4 , with a maximum total score of 56. After completing the Berg Balance Scale, participants were instructed about the practice session. All participants in both groups performed a 15 minutes wobble board practice session, before starting the computer maze practice session while standing normally. The practice session for the maze task was a shorter version of the actual experimental session that includes only one block of five trials. The reason for the maze practice session is to further compare any prior spatial memory differences between the single and the dual task group. After the maze practice session, both groups moved on to the experimental session, which the dual task group performed on a wobble board and the single task group performed in a normal standing position. For both groups the instructions for the maze were as follows:

"During the experiment, you will see a round pool on the computer screen. Please imagine that you are in this pool. Your objective in the experiment is to find the hidden platform. You have to use the game console pad to help you navigate in the pool. You cannot see the platform while you are on the move, however when you pass the platform you will see "platform found" written on the screen. The first trial will be the platform discovery stage. In this initial trial, you will try to find the platform by exploring the pool. When you find the platform, the discovery stage will end. In the following four trials, your task is to remember the location of the hidden platform and to find it as fast as possible. In all of these four trials, you will have a different starting point in the pool in relation to surrounding objects. You can take advantage of these different colored objects placed around the pool to remember the location of the hidden platform. In total there are going to be 4 blocks of 5 trials." 
The dual task group were instructed to follow the additional instructions, "Every mistake you make while standing on the balance board will be recorded. That is why you need to be as balanced as possible (minimize your sways). Please try keep your eyes on the computer screen". Both groups were given a 30 seconds relaxation break after each learning block.

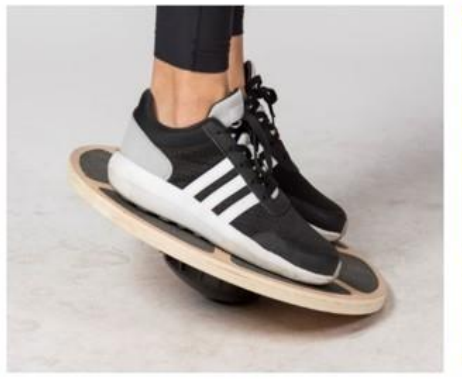

15 minutes balance board training

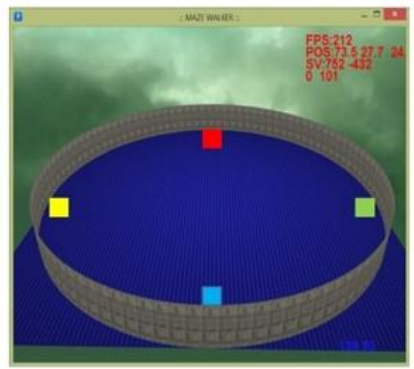

Practice Standing Normal (1 Block)

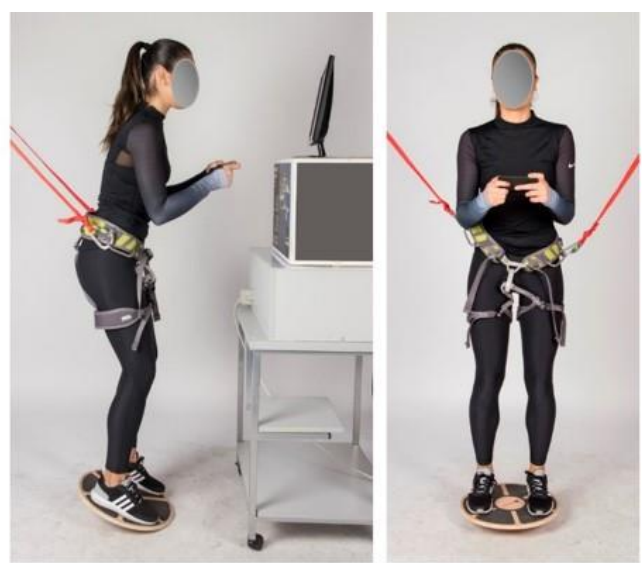

Test phase

Dual Task

(4 Blocks)
15 minutes balance board training
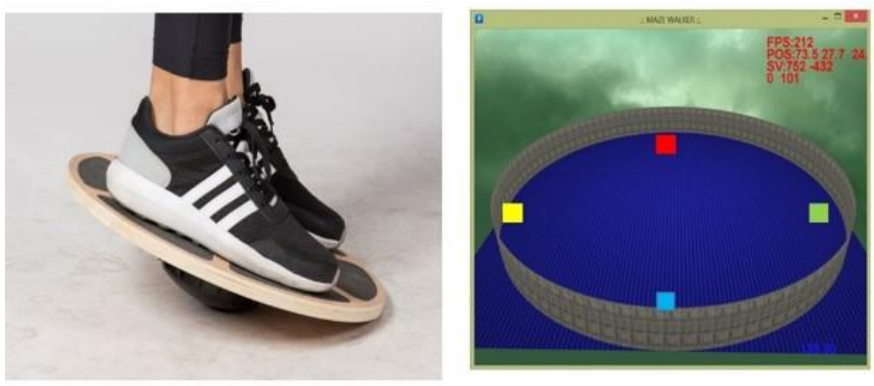
Standing Normal

(1 Block)
Practice

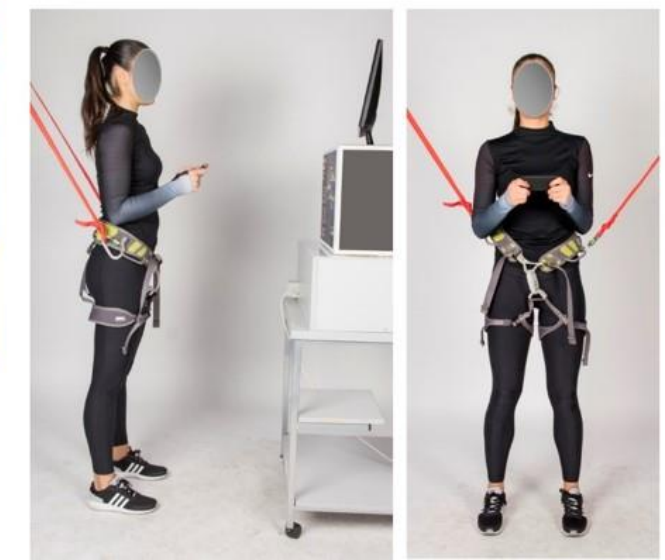

Figure 1. Representative demonstration of the experimental procedure. 


\section{Participants}

Participants were sixty-eight healthy young adults (34 females mean age 20.77 years $(S D=2.34)$ and 34 males mean age $21.38(S D=1.89)$ from the undergraduate population. When signing up to the experiment, potential participants were asked to fill an evaluation form to determine eligibility. Several inclusion and exclusion criteria were set, and potential participants were excluded if one of the following criteria was met: (i) being diagnosed with a vestibular disorder (ii) physical injury to neck or joint, (iii) having abnormal or corrected-tonormal visual acuity (i.e., wearing glasses), (iv) previous experience of wobble board, and (v) previous professional experience of ballet, aerobic, yoga or sports activities. Furthermore for male participants heavier than $90 \mathrm{~kg}$ and taller than $190 \mathrm{~cm}$ were excluded. Similarly, females heavier than $70 \mathrm{~kg}$ and taller than $180 \mathrm{~cm}$ were not included in the study. After the experiments were scheduled, all participants were asked to wear comfortable sports shoes and clothes for the experiment. All participants signed an inform consent sheet before the experimental session, and were randomly assigned to either the dual or single task condition. In addition, all participants were asked to complete a questionnaire about the frequency of computer-gaming experience on a 5-point scale (1 indicates I never play and 5 indicates I play every day). During the experiment, no participant experienced a fall, and therefore the total dropout out rate was considered as $0 \%$. The study was approved by İzmir University of Economics Ethics board.

\section{Stimuli and Apparatus}

Maze environment and Spatial Learning Task. The original Morris Water maze (MWT) hidden platform task (Morris, 1981) was primarily designed to measure spatial learning and recall in rats, and over the last three decades it has been used to evaluate the effects of aging (de Fiebre et.al., 2006; Lindner,1997), and experimental lesions (Morris et.al.,1982; Smith et.al.,1991; Nagahara, Otto, \& Gallagher,1995). More recently, virtual versions of the water maze were developed for use in human research (Burgess, Maguire \& 
O'Keefe, 2002). It was showed that virtual MWT have behavioral (Jacobs, Laurence \& Thomas, 1997) and neurobiological (Hamilton, Driscoll \& Sutherland, 2002; GoodrichHunsaker, et al., 2010; Skelton \& Hopkins, 2010) significance, showing similarities between humans and rodents in spatial memory acquisition (Sandstrom, Kaufman \& Huettel, 1998; Montello et al., 1999; Jansen-Osmann \& Wiedenbauer, 2004). It was also validated with various patient groups, such as those with hippocampal dysfunction (Jacobs, Laurence \& Thomas, 1997; Cornwell, et al., 2008; Goodrich-Hunsaker, et al., 2010), and with Schizophrenia (Hanlon et al., 2008). Here, the task used was a virtual analogue of the classic MWM hidden platform task (with a three-dimensional pool) called Maze Suite application (Ayaz et al. (2008), copyrighted by Drexel University and obtained from Maze Suite webpage (mazesuite.com/downloads). The maze environment was created using the Maze Suite application, which enables the creation of 3D virtual environments. Maze Suit has three applications: MazeMaker, MazeWalker and MazeAnalyzer. MazeMaker is the editor application for creating and editing, MazeWalker is the application that renders mazes created by MazeMaker, and MazeAnalyzer is used to calculate the duration to finding the hidden platform and path length. All of the experiments were run in a computer with Intel Core i74790K 4.00GHZ processor with 16 GB RAM (200 MB reserved) in a 64 bit Windows 10 operating system. The computer graphics card that ran the simulations is an NVIDIA GEFORCE GTX 970 (4GB). All of the experiments were run on a constant 60 frames per second refresh rate 22 " LCD computer screen throughout the whole experience. It is important to note that for both groups, the computer screen was standing approximately 50 $\mathrm{cm}$ away from the participants, with a visual field angle of $90^{\circ}$, which was adjusted based on the participants height.

In the spatial memory task, participants repeatedly learned a target location in relation to four distinct landmarks. The landmarks were different coloured rectangles in the pool, and 
blue floor represents water (see Figure 2). During the first discovery trial, participants learned the location of the platform, and in the following four test trails, they attempted to find the location of the hidden platform. Each block consists of one discovery trial and four test trials. The location of the hidden platform was same during all trials, but the starting point changed for each test trial. Participants navigated a total of 4 blocks and the duration to find the hidden platform and path length was recorded. The location of the hidden platform was counterbalanced between participants.
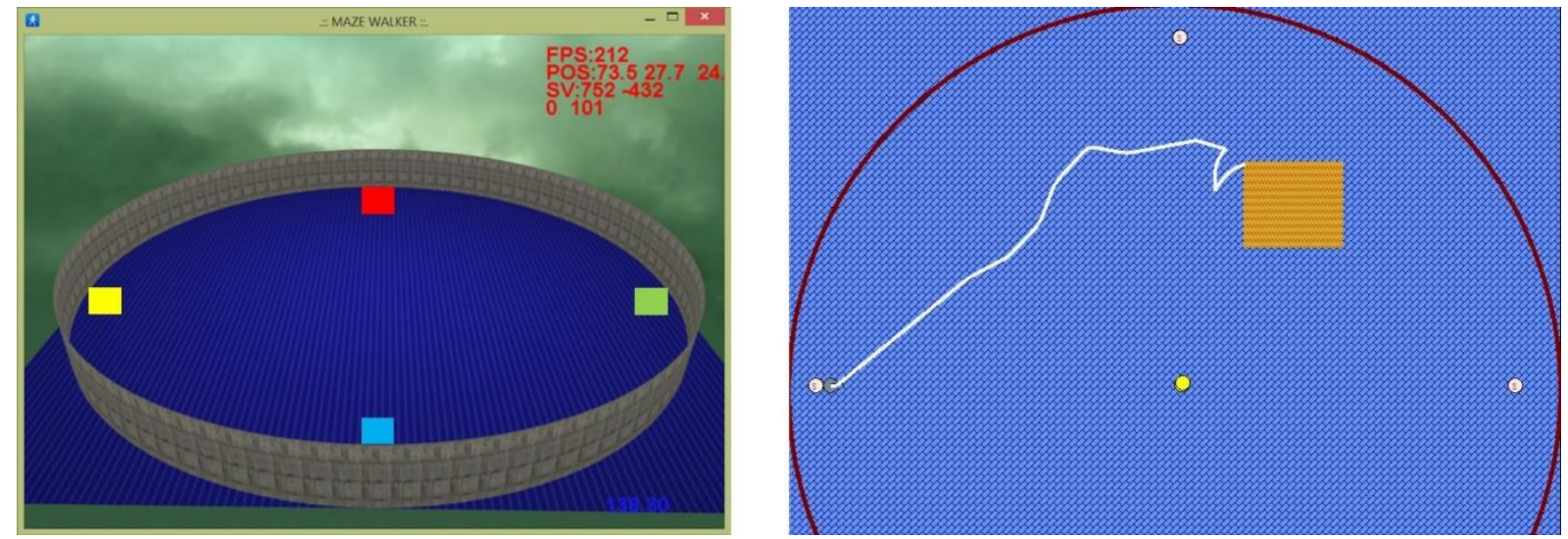

Figure 2. On the left, there is a view of the virtual Morris Water Maze task. Red, green, yellow and blue boxes indicated landmarks. On the right, there is a birds' eye view of the maze, white circles indicate landmarks and the square shows the location of the hidden platform.

Postural Control Task. One of the most important aspect of postural stability and balance is the ability to control the body's center of mass (COM) relative to the base of support. The standing equilibrium is defined as the area in which one can move the COM at their base of support and maintain equilibrium on stable or unstable surfaces. Previous studies used various balance training techniques such as wobble boards (Bernier \& Perrin, 1998; Eils \& Rosenbaum, 2001), ankle disks (Eils \& Rosenbaum, 2001; Gauffin, Tropp, \& Odenrick, 1998) and mini trampolines (Kidgell et al., 2007). These studies showed that training produces improvements in proprioception (joint position sense) in the ankle (Waddington \& 
Adams, 2004) and the knee (Diracoglu, Aydin, Baskent, \& Celik, 2005). In the current study, the postural control task was to maintain maximum equilibrium while standing with both feet on a wobble board (www.domyos.com). Due to fluctuations of the support base of the wobble board, subjects need to maintain their posture. The wobble board was made of hard wood and has dimensions of $39.5 \mathrm{~cm}$ diameter and $7.5 \mathrm{~cm}$ height. Performance was measured by the total number of postural sway errors on the wobble board. During postural control task, two independent raters recorded the number of postural sway errors, defined as when lateral surfaces of the board made contact with the floor (see Berg et al., 1989 and Berg et al., 1995 for similar rating methods). The independent raters carefully monitored the duration of these errors and if the surface of the board made contact for longer than $\sim 5$ seconds, that trial was excluded from the analysis. During the experiment, participants were fastened with a harness (mountain rock climbing safety belt with seat strap) in order to prevent falls. In addition, when the participants made a mistake they had to re-establish their balance themselves without help from the experimenter. This safety measure was necessary because participants held a game pad to navigate the maze and were unable to hold anything else. In the dual task condition, participants were instructed to minimize their sway, and remain as stable as possible while they performed the search for the hidden platform in virtual MWT. They were advised to stand as comfortably as possible with heels approx.10 $\mathrm{cm}$ apart. Finally, during the experiment, there were no falls, injuries or delays in the experimental session.

\section{Results}

\section{Computer Game Experience}

A 2 (male, female) x 2 (single task, dual task) independent samples ANOVA revealed that there is a significant main effect of gender on participants' 3D computer game experience, $F(1,64)=52.30, p<.001$, partial $\eta^{2}=.45$. Male participants $(M=2.53, S D=0.20)$ play $3 \mathrm{D}$ 
computer games more often than female participants do $(M=0.85, S E=0.12)$. However there was no significant main effect of condition, $F(1,64)=0.15, p=.71$. Furthermore there was no significant interaction effect between gender and condition, $F(1,64)=0.15, p=.71$.

\section{Berg Balance Scale}

The mean Berg balance score of participants was $55.62(S D=1.08)$ out of 56. A 2 (male, female) x 2 (single task, dual task) two-way independents samples ANOVA that compare the Berg balance scale performance showed no significant difference between the dual task condition and single task condition, $F(1,64)=0.81, p=.37$. Additionally, we found no significant difference between male and female participants, $F(1,64)=1.82, p=.18$. The interaction effect was also non-significant $F(1,64)=0.46, p=.50$ indicating no differences in Berg Balance Scores across experimental conditions.

\section{Practice Session}

In order to rule out prior experience with the spatial memory task, both groups performed the task standing normally on their feet. The comparison of the sex differences during this single block maze learning performed by a 2 (male, female) x 2 (dual task, single task) two-way independent samples ANOVA. The results revealed that males $(M=42.89, S E$ $=2.59)$ were faster than females $(M=101.65, \mathrm{SE}=11.37)$ in finding the hidden platform, $F(1$, 64) $=25.39, p<.001$, partial $\eta^{2}=.28$. However, there was no significant difference between participants in single task and dual task conditions on the duration, $F(1,64)=1.48, p=.23$. Also, the interaction effect of gender and condition was not statistically significant, $F(1,64)=$ $0.51, p=.48$. Another 2 (male, female) $\times 2$ (dual task, single task) two-way independent samples ANOVA was conducted on path length measurement. Results showed that males used shorter path length than females $(M=202.47, S E=21.90$ when finding the hidden platform, $F(1,64)$ $=12.42, \mathrm{p}=.001$, partial $\eta^{2}=.16$. However, there was no significant main effect of condition, 
$F(1,64)=1.34, p=.25$, and no significant interaction effect of gender and condition, $F(1,64)$ $=.37, \mathrm{p}=.55$ (Figure 3). Overall, the training session showed males' superior performance in the virtual Morris Water Maze. However, participants assigned to single and dual task condition showed no previous advantage on their performance in virtual Morris Water Maze.

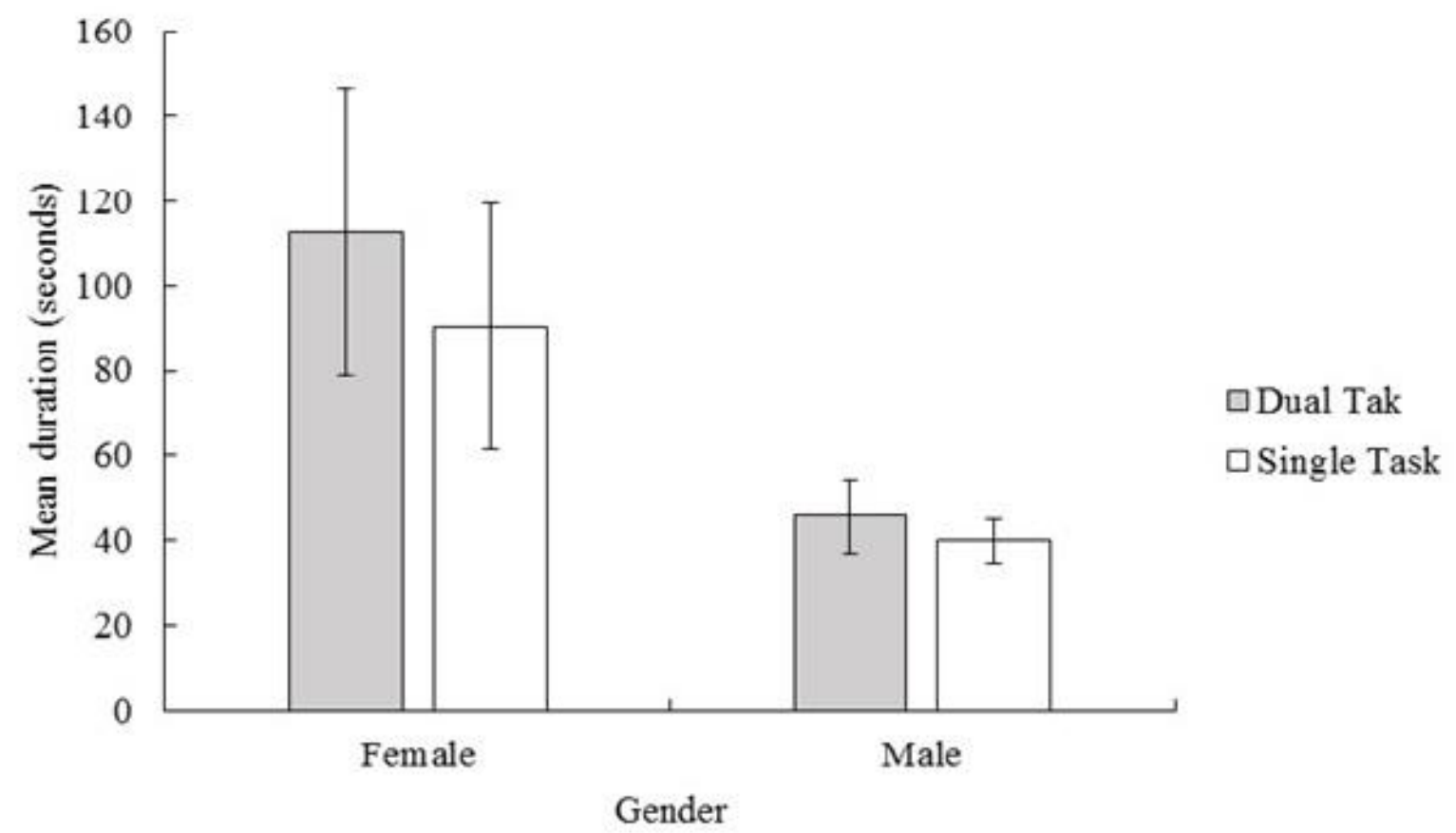

Figure 3. Mean duration (with $95 \% \mathrm{CI}$ ) of participants on finding the hidden platform in training session. 


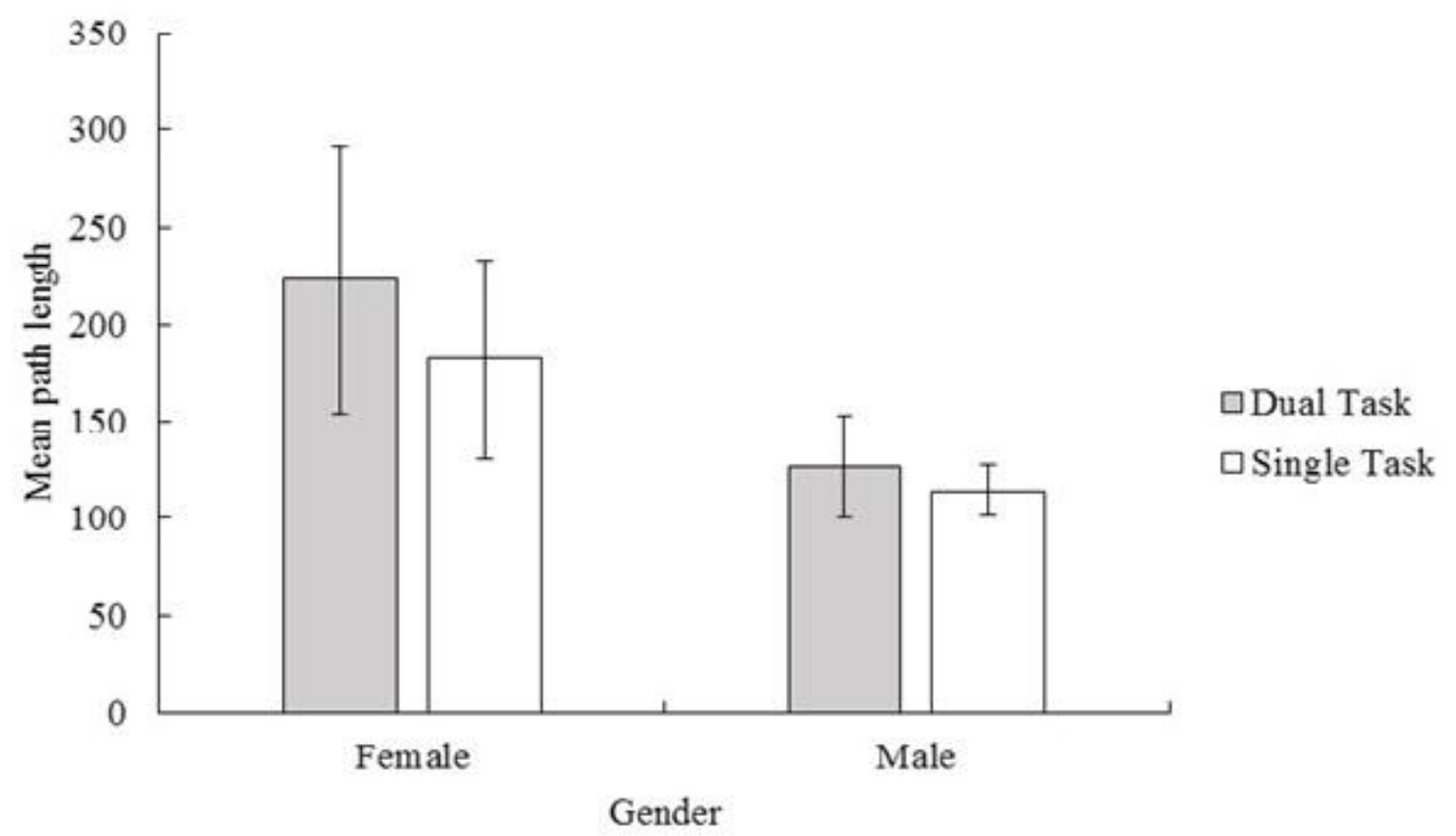

Figure 4. Mean path length (with 95\% CI) of participants on finding the hidden platform in training session

\section{Experimental Session}

Postural Sway Performance. Previous studies found controversial results regarding gender differences in balance performance on a wobble board, based on age (Sugiura et al., 2017). However, a recent study by Fusco and colleagues (2018) found no significant gender difference in healthy young adults. Within and between rater reliability was calculated using intra class correlation coefficients (ICC), while showed high reliability between rates (ICC, 91) and high within reliability (ICC, 93) with 95\% CI. Furthermore, in order to examine gender differences, mean scores of two independent rates were analysed as follows: A 2 (male, female) x 4 (block1, 2, 3, 4), gender as between subjects and block as within subjects' variable, two-way mixed factorial ANOVA was conducted to identify any significant difference between males and females in different blocks on their number of errors while on wobble board. The total mean number of errors when participants in dual task condition was $14.83(S D=8.40)$. Furthermore, the results showed no main effect of gender, $F(1,31)=$ 
$1.47, p=.24$. Mauchly's test indicated that the assumption of sphericity is violated, $\chi^{2}(5)=$ $13.46, p=.02$, therefore Huyn-Feldt corrected tests are reported $(e=.89)$. Thus, there was a significant main effect of blocks, $F(2.66,82.48)=6.05, p=.001$. Planned contrasts revealed a significant difference between blocks 1 and $2, F(1,31)=6.47, p=.02, r=.42$, but no significant difference between blocks 2 and $3, F(1,31)=0.01, p=.94$, and block 3 and block $4, F(1,31)=3.57, p=.07$. Furthermore, interaction effect of gender and block was not statistically significant, $F(2.66,82.48)=0.09, p=.95$ (Figure 5).

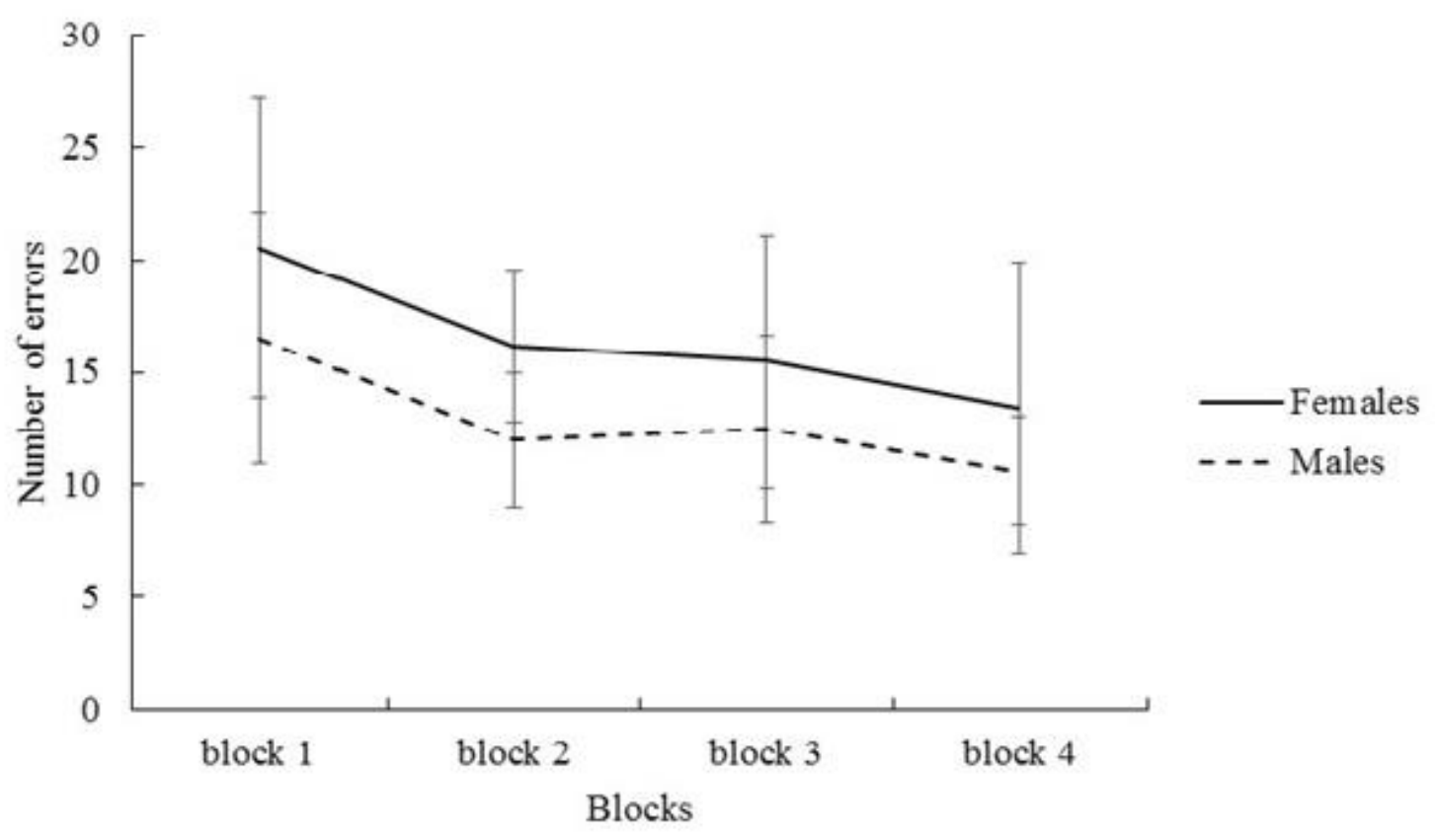

Figure 5. Mean number of errors (with 95\% CI) when participants in dual task condition on wobble board.

Spatial Memory Performance. A 2 (male, female) x 2 (single task, dual task) x 4 (block 1, 2, $3,4)$, gender and condition as between subjects and block as within subjects variable, threeway mixed factorial ANOVA was conducted to determine whether gender, condition and block in the experiment had any effect on duration of finding the hidden platform. Results showed a significant main effect of gender, $F(1,64)=56.67, p<.001$. Males $(M=38.15, S E$ $=1.51)$ perform faster than females $(M=73.42, S E=5.09)$. Furthermore, the main effect of 
condition was significant, $F(1,64)=15.70, p<.001$. Participants in the single task condition $(M=46.50, \quad S E=3.03)$ found the hidden platform faster than those in the dual task condition $(M=65.07, S E=5.71)$. The interaction effect of gender and condition was also significant, $F(1,64)=4.88, p=.03$. In order to break down the interaction effect, a simple effect analysis was conducted. Results revealed that for females, there was a significant difference between dual task and single task condition, $F(1,64)=19.05, p<.001$. As seen in Figure 6, females took longer to find the hidden platform in the dual task condition $(M=$ 87.88, $S E=8.10)$ than in the single task condition $(M=58.96, S E=3.86)$. However, this difference was not observed in male participants. Analysis revealed no significant difference between dual task $(M=42.26, S E=1.96)$ and single task conditions $(M=30.04, S E=1.85)$ in males, $F(1,64)=1.54, p=.22($ Figure 6$)$.

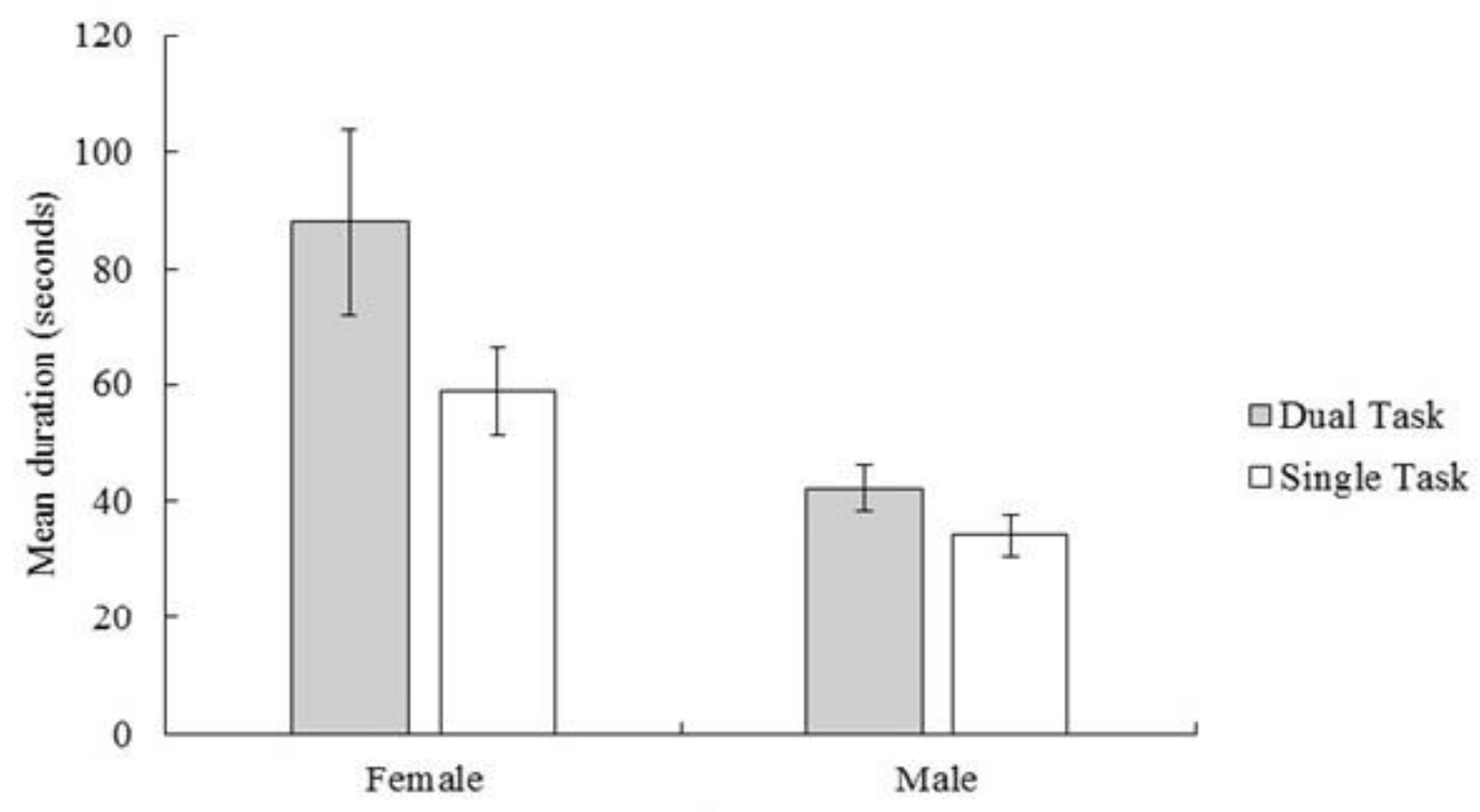

Gender

Figure 6. Mean duration (with $95 \%$ CI) of participants on finding the hidden platform in test session.

Another 2 (male, female) x 2 (single task, dual task) x 4 (block 1, 2, 3, 4) three-way mixed ANOVA was conducted to understand whether gender, condition and blocks in the 
experiment had any effect on path length measurements when participants were searching for the hidden platform. Results revealed a main effect of gender, $F(1,64)=16.15, p<.001$, partial $\eta^{2}=.20$. Males $(M=114.84, S E=114.84)$ used shorter paths than females $(M=155.31$, $S E=10.35)$. Also, there was a significant main effect of condition, $F(1,64)=9.90, p=.003$, partial $\eta^{2}=.13$. Participants in single task condition $(M=119.23, S E=4.98)$ used shorter paths than participants in dual task condition $(M=150.91, S E=10.22)$. Furthermore, there was a significant interaction effect of gender and condition, $F(1,64)=4.00, p=.05$, partial $\eta^{2}=.06$. A simple effect analysis was conducted to breakdown the interaction effect, which showed that, females used longer paths in the dual task condition $(M=181.21, S E=17.15)$ than in single task condition $(M=129.40, S E=8.00), F(1,64)=13.23, p=.001$. However, for males this difference in path length measurement was not observed. Results showed that there was no significant difference between single task $(M=109.07, S E=5.03)$ and dual task $(M=120.62$, $S E=4.72$ ) path length measurements in male participants, $F(1,64)=0.66, p=.42$ (Figure 7).

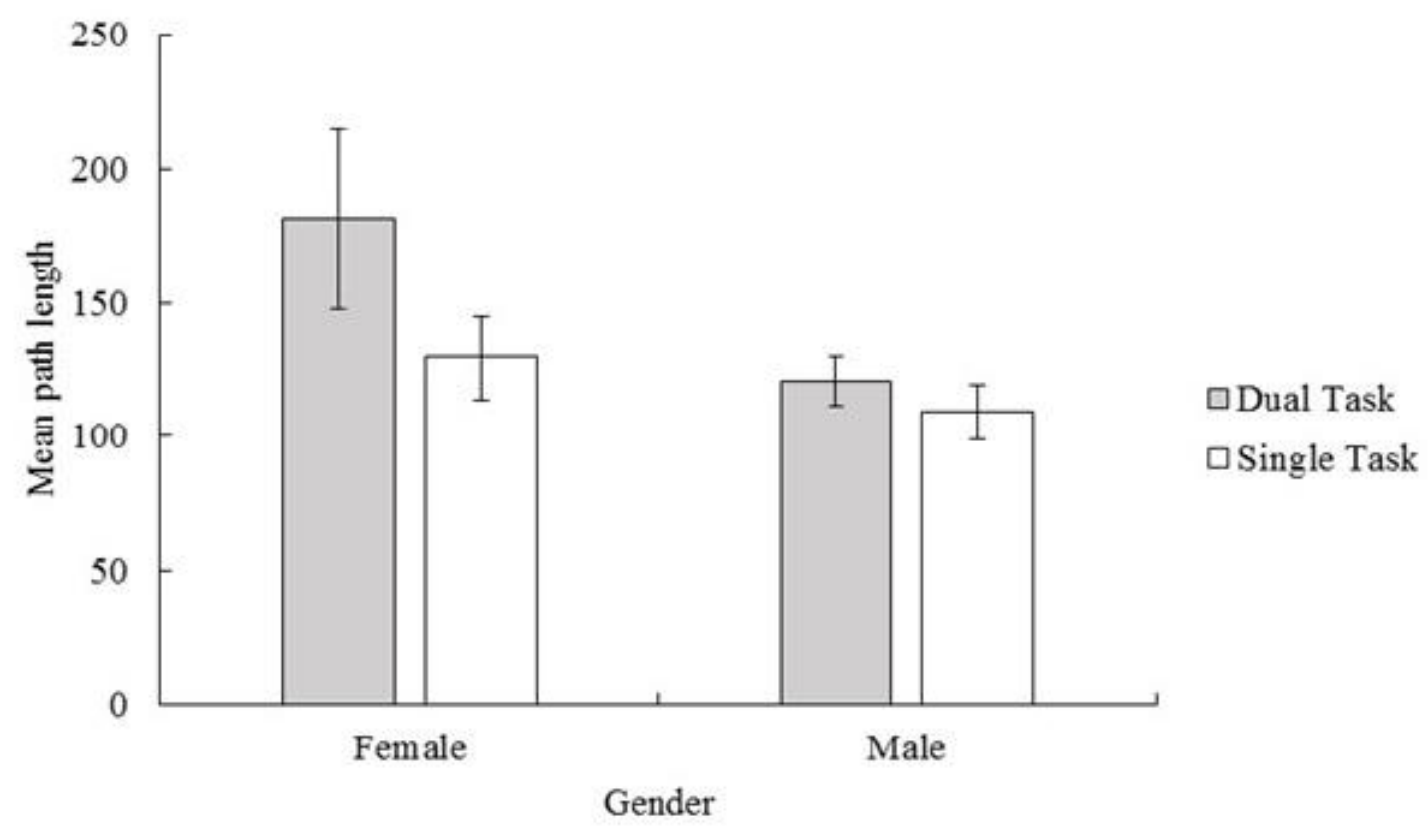

Figure 7. Mean path length (with $95 \% \mathrm{CI}$ ) of participants on finding the hidden platform in test session. 
The Influence of Computer Game Experience. In the current study, although we aimed to minimize the role of prior gaming experience by including a training session, it is possible that prior computer game experience could have induced the male advantage. In fact, the primary comparison on the gaming experience questionnaire showed that males had significantly greater experience. It is possible that gaming experience influences the differences in performances between sexes (Schmitz, 1997). Previous studies showed that early recreational activities have often been cited as a major cause of gender differences in adult spatial cognition (e.g., Baenninger \& Newcombe, 1989; Law, Pellegrino, \& Hunt, 1993; McClurg \& Chaille, 1987; Castel, Pratt, \& Drummond, 2005; Green \& Bavelier, 2003, 2006, 2007). In fact, a previous study by Feng and colleagues (2007) showed that a 10-hour action video game increased females' spatial cognition performance significantly more than male's. Supporting this explanation, Waller (2000) found that gender affects acquisition of spatial information in a virtual environment, primarily through its association with the ability to understand the interface of the virtual environment; when this was factored out, gender differences were shown to be minimal.

In order to control for the computer game experience, we re-analyzed the data including the prior game experience as a covariate. In order to that a 2 (male, female) x 2 (single task, dual task) x 4 (block 1, 2, 3, 4) repeated measures ANOVA were conducted on duration of finding the hidden platform, this time by adding the frequency of participants game experience to the model as a covariate. Mauchly's test indicated that the assumption of sphericity had been violated, $\chi^{2}(5)=70.13, p<.001, e=.59$. Therefore, Greenhouse-Geisser corrected results will be reported. Results revealed that game experience had no effect on duration of finding the hidden platform, $F(1,63)=1.10, p>.05$. Furthermore, adding computer game experience to the model did not change the previous finding. The results showed that there is a significant main effect of block, $F(1.77,111.72)=5.94, p<.01$, partial $\eta^{2}=.09$. Simple contrasts revealed 
that there was no significant difference between block 1 and block $2, F(1,63)=3.72, p>.05$. However, duration of finding the hidden platform was shorter in the third block, $F(1,63)=$ $8.22, p<.01$ and forth block, $F(1,63)=8.46, p<.001$ compared to the first block. Males were still faster than females, $F(1,63)=1,63, p<.001$, partial $\eta^{2}=.28$ and single task condition participants were significantly faster than dual task condition participants $F(1,63)=15.30, p$ $<.001$. Interaction effect of the gender and task was also intact, $F(1,63)=4.66, p<.05$ (Figure 8 and Figure 9).

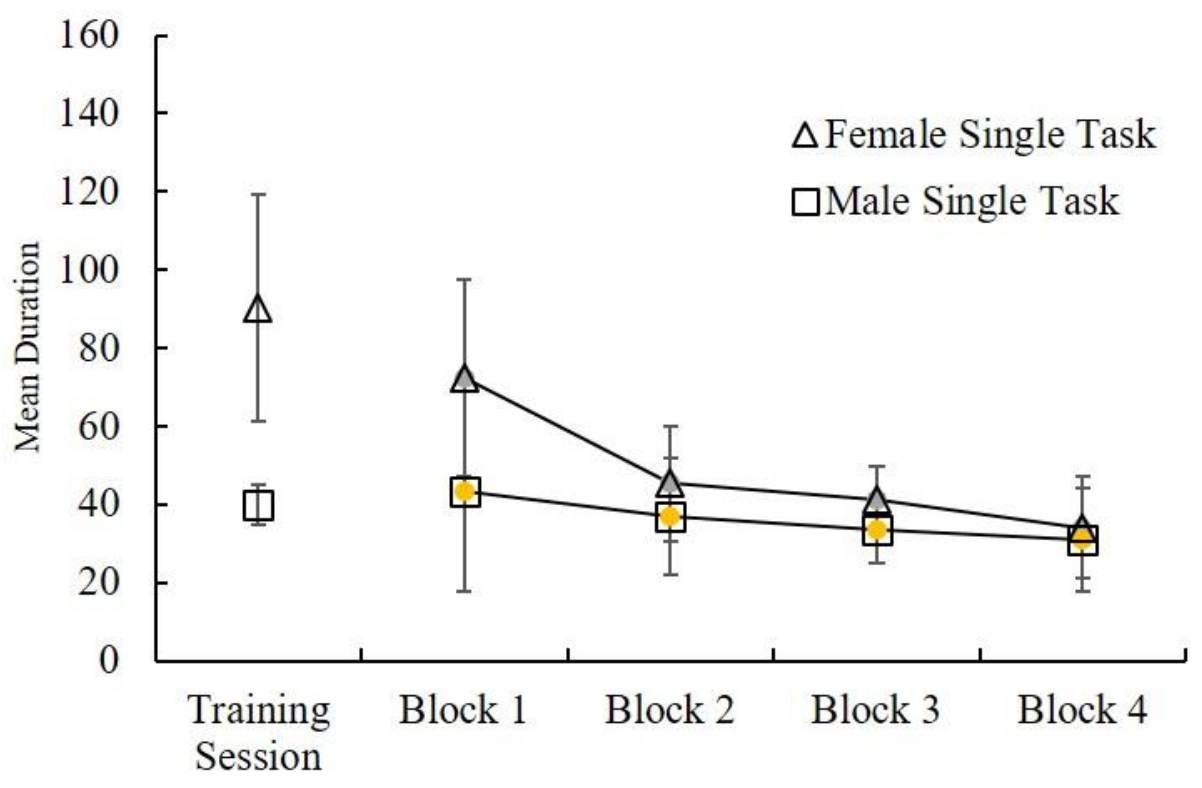

Figure 8. Mean duration (with $95 \% \mathrm{CI}$ ) of participants on finding the hidden platform during single task. 


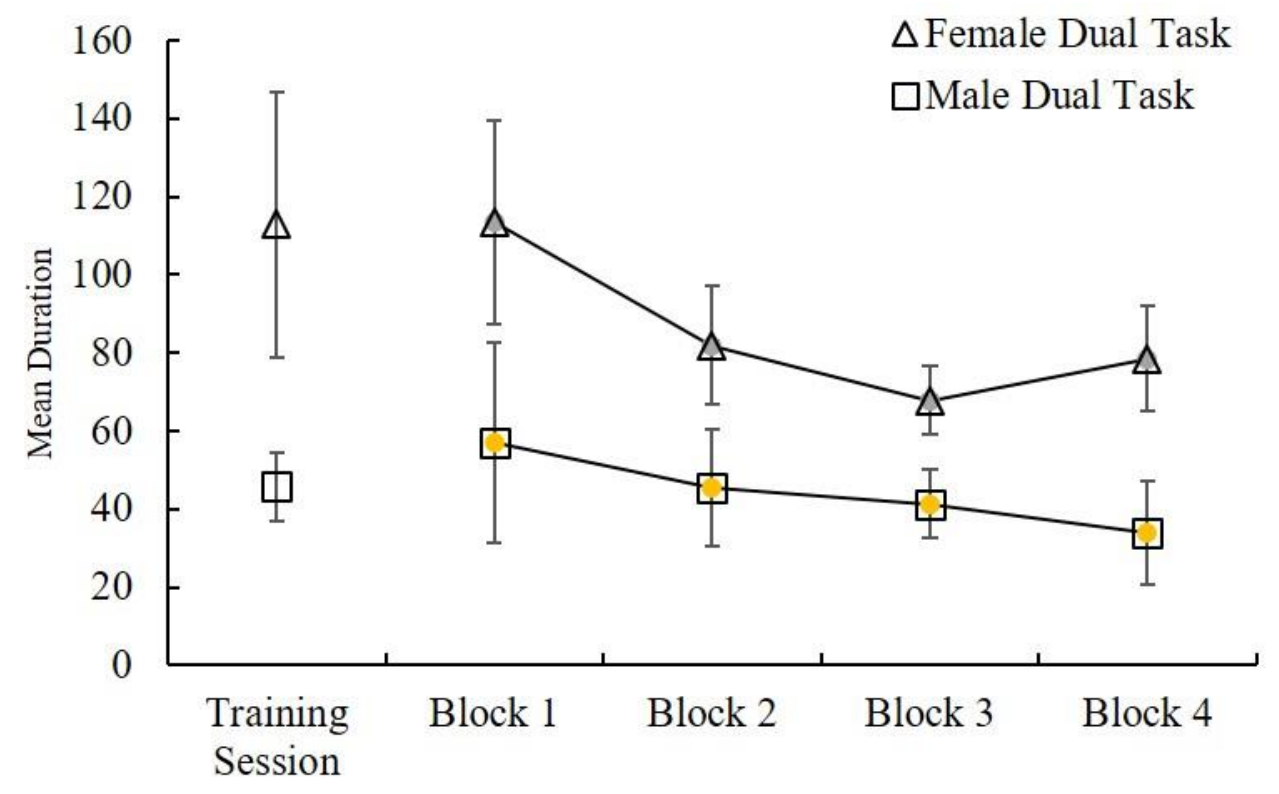

Figure 9. Mean duration (with 95\% CI) of participants on finding the hidden platform during dual task.

Similarly, a 2 (male, female) x 2 (single task, dual task) x 4 (block 1, 2, 3, 4) repeated measures ANOVA was conducted on path length by adding computer game experience as a covariate. Mauchly's test indicated that the sphericity assumption had been violated, $\chi^{2}(5)=$ 74.37, $p<.001, e=.56$. Therefore, Greenhouse-Geisser corrected results are reported. Results showed that there was no effect of participants' game experience on path length measurement, $F(1,63)=1.49, p>.05$. Furthermore, controlling computer game experience did not change the previous results. There was a main effect of block on path length measurement, $F$ (1.69, $106.21)=4.34, p<.05$, partial $\eta^{2}=.06$. Simple contrasts revealed that there was no significant difference between the first and the second block, $F(1,63)=3.56, p>.05$. However, in the third block, $F(1,63)=6.30, p<.05$ and the fourth block $F(1,63)=5.35, p<.05$, the path length of participants was shorter compared to the first block. Furthermore, male participants had superior performance compared to females, $F(1,63)=5.09, p<.05$ partial $\eta^{2}=.08$, and the single task group compared to the dual task group, $F(1,63)=9.30, p<.01$ partial $\eta^{2}=.13$. 
In addition, the interaction effect of gender and condition was still present, $F(1,63)=4.16, p$ $=.05$, partial $\eta^{2}=.06$ (Figure 11). The results showed that when we include the computer game experience as a covariate in the analysis, there was no significant change on the outcome, the results remained the same.

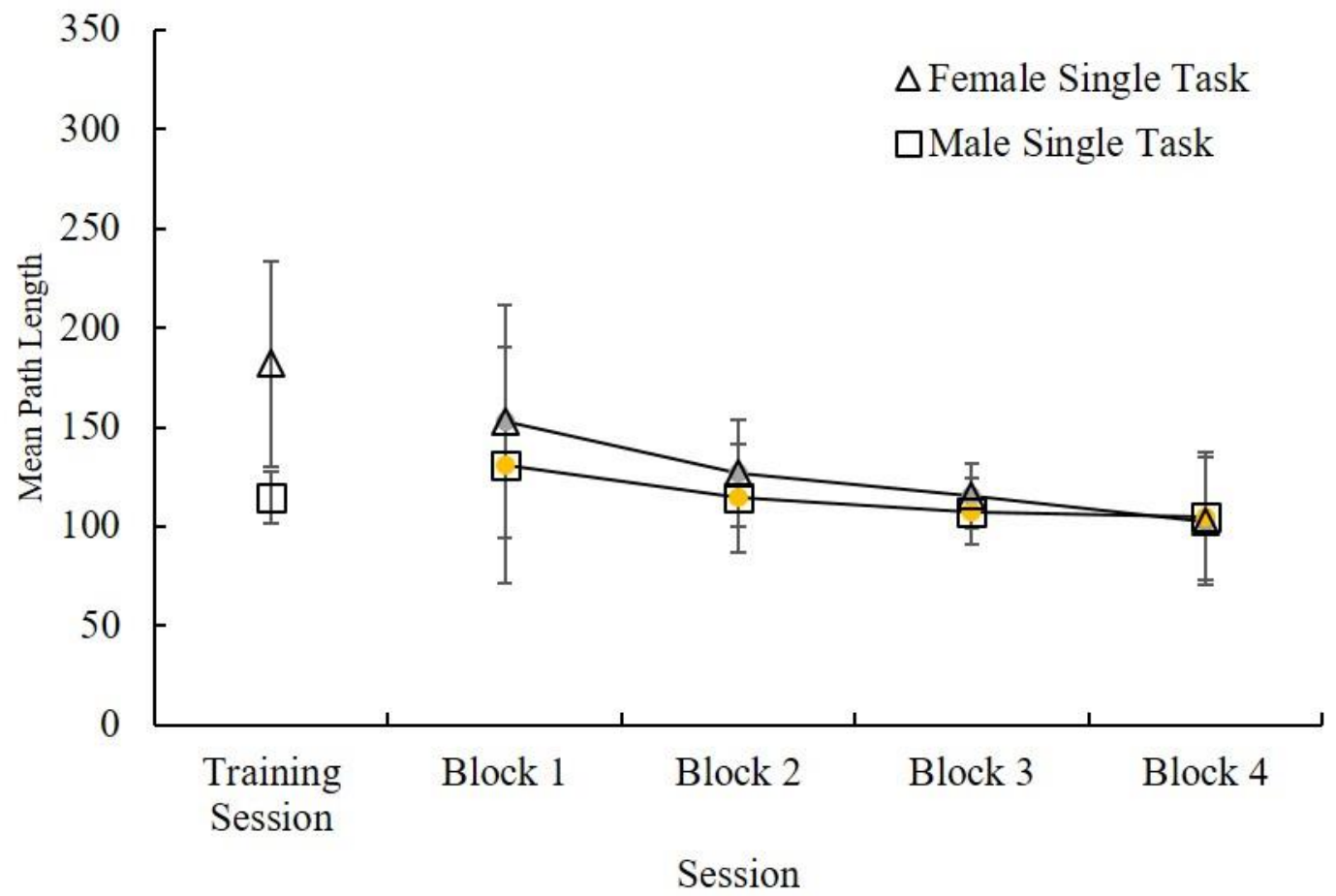

Figure 10. Mean path length to find the hidden platform (with 95\% CI) of participants on finding the hidden platform during single task. 


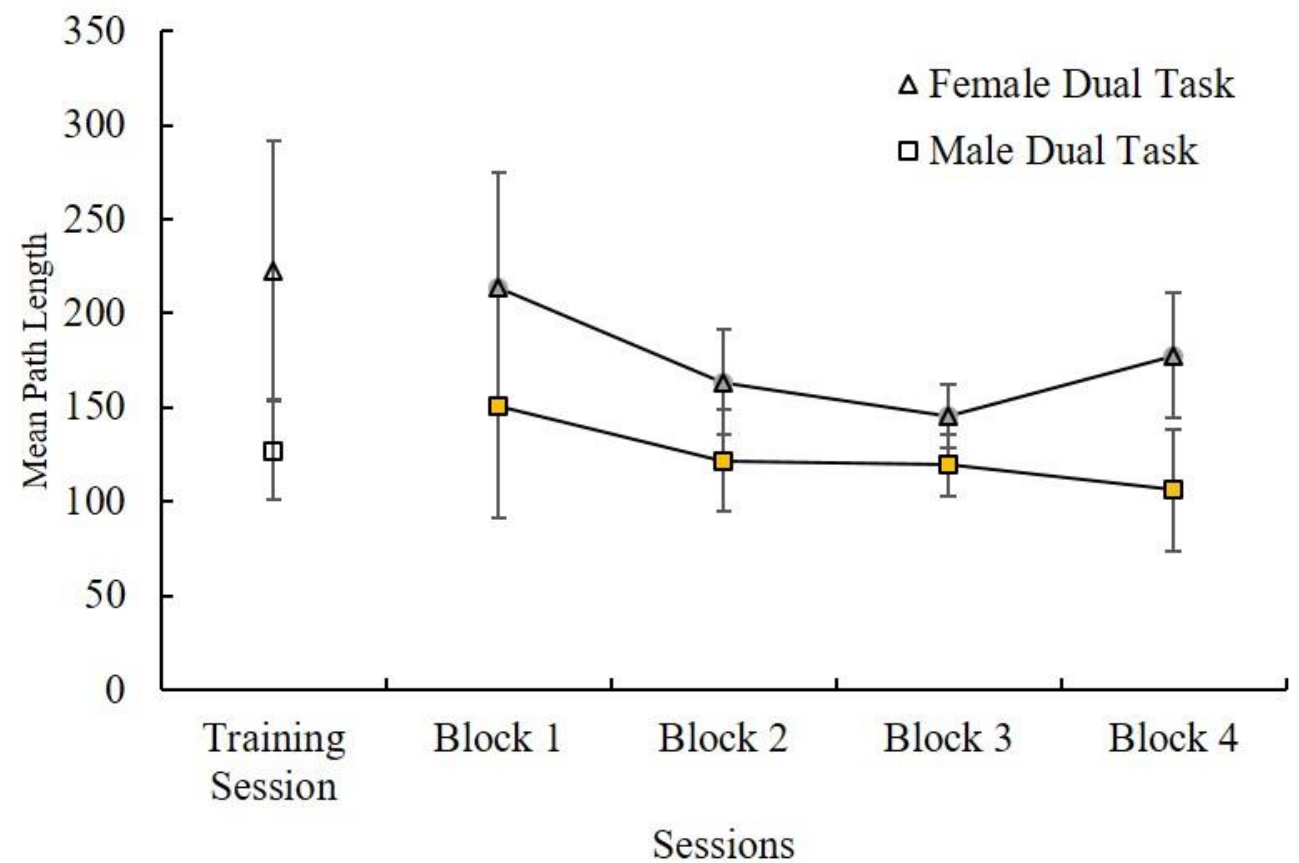

Figure 11. Mean path length to find the hidden platform (with $95 \% \mathrm{CI}$ ) of participants on finding the hidden platform during dual task.

\section{Discussion}

In the current the study, we examined the influence of the wobble board on spatial learning skills, focusing on the sex differences between males and females performances. The results showed that wobble board significantly impaired the spatial learning performance of female participants but not males. More specifically, female participants in the dual task condition were significantly slower, and used longer paths than male participants, even though there was no significant difference in the motor performance during (i.e, postural sway errors) or prior to (i.e, Berg balance test) to the dual task. Moreover, including the prior computer game experience in the statistical model does not make any changes to the results; on contrary, during the single task condition, male participants showed superior performance in the training session; however, female participants quickly caught up in the following blocks, and no significant differences in the spatial learning performance was observed. 
There are several plausible reason for this. Firstly, previous research has showed that information from the proprioceptive system is highly beneficial during spatial learning, due to information from body movements, which are used to update the egocentric spatial reference frame (Chance et al., 1998; Wraga et al., 2003) and used in the coding of the up/down, right/left, and front/back positions of an observer (Filimon, 2015). Secondly, studies showed that visual information alone, without concomitant body rotation, were insufficient to induce egocentric updating (see also Chance, et al., 1998; Bakker, Werkhoven, \& Passenier, 1999). Based on the results of the current study, we can make the case that the efficiency and accuracy of egocentric updating may rely on the compatibility between the body rotation during standing, and rotation towards the actual location of the hidden platform. During a normal standing navigation task, the body's sway and rotation generally results in either forward/backward or right/left movements in the direction of target object; however, on a wobble board, participants spin and tilt might cause multidirectional perturbations on body rotation and sway. It is plausible that this incompatibility between the actual body position and predicted direction of the movement towards the hidden platform might have impaired the performance of females by interfering with the ability to update egocentric spatial reference frame.

Moreover, the results showed that male participants used significantly shorter paths and found the hidden platform faster than females, in both the training and the testing phases during dual tasking. This finding suggests that males may have an advantage over females not only in the maze learning, but also during dual task performance. Previous studies showed that in virtual mazes, compared to females, males typically locate the hidden platforms faster, covering smaller distances (Astur, Ortiz \& Sutherland, 1998; Astur, et al., 2004; Driscoll et al., 2005; Tlauka et al. 2005; Mueller, Jackson \& Skelton, 2008). It was also demonstrated that during navigation, female participants rely more on landmarks, and men more on geometric properties (Dabbs, et al., 1998; Galea \& Kimura, 1993; Astur et. al, 2004; Moffatt et al., 1998; Sandstrom 
et al., 1998). In tasks that rely on positional (landmark) cues, women perform at least as well as men (Astur et al., 2004; Levy, Astur, \& Frick, 2005; O’Laughlin \& Brubaker, 1998; Saucier et al., 2002); while in maze navigation tasks where such cues are absent, shifted, or removed during testing, females' performance is much more impaired than males' (Moffat et al., 1998; Sandstrom et al., 1998; Saucier et al. 2002). In the view of these findings, at least equal performance was expected in the current study, because both during learning and searching trials, landmark cues were present on the maze. One possible reason the differences in performance might be related to the differences in brain regions used for navigation. Grön, et al., (2000) showed that men primarily engaged the left hippocampal region, and women, the right parietal and right prefrontal areas during a navigation task. This suggests the possibility that females were already using these regions for the spatial memory task and were involved in providing additional cognitive resources for dual task compensation.

Another possible explanation given by Waller, Knapp, and Hunt (2001) is that virtual environments may be more challenging for women due to disorientation in virtual mazes. This is consistent with the results of the current study; a comparative analysis of performance over blocks of trials shows performance of males is stable, while females improve. It is therefore plausible that gender-related differences are associated with prior experience rather than gender superiority.

\section{Limitations}

Several important limitations of the current study deserve mention. Due to a lack of suitable motion capturing equipment, it was not possible to track the body movements during performing the task. This might have helped understanding of the reactive strategies that individuals employ to maintain their center of mass (CoM). Secondly, there was no recording of the latency of contacts to the floor during error calculation, tilt angle measurements or 
rotations of the wobble board on the main axis, which would have given a more accurate definition of the type of differences observed by males and females. These limitations can be eliminated in the future by using two different types of balance board, with one having only free $360^{\circ}$ rotational disc and another with vertical tilting. We are also developing a smart wobble board with force plate and accelerometer similar to that of Williams and Bentman (2014), potentially improving performance measurement (see also Sugiura et al., 2017 and Fusco et al., 2018).

\section{Conclusion}

The main finding of the current study is that the improvement in spatial memory performance paralleled the improvement in postural control, and that the males showed greater gains in both tasks. It was also showed that females' spatial memory performance was negatively affected by the postural control task, despite the lack of significant difference between males and females for postural sway errors on the balance board. Our results therefore suggest that balance training on a wobble board influences spatial memory in females, whereas males showed no improvement during the dual tasking. 


\section{References}

Abernethy, B. (1988). Dual-task methodology and motor skills research: some applications and methodological constraints. Journal of Human Movement Studies, 14(3), 101-132.

Andersson, G., Yardley, L., \& Luxon, L. (1998). A dual-task study of interference between mental activity and control of balance. Otology \& Neurotology, 19(5), 632-637.

Astur, R. S., Ortiz, M. L., \& Sutherland, R. J. (1998). A characterization of performance by men and women in a virtual morris water task: A large and reliable sex difference. Behavioural Brain Research, 93(1-2), 185-190. https://doi.org/10.1016/S0166-4328(98)00019-9.

Astur, R. S., Tropp, J., Sava, S., Constable, R. T., \& Markus, E. J. (2004). Sex differences and correlations in a virtual Morris water task, a virtual radial arm maze, and mental rotation. Behavioural Brain Research, 151(1-2), 103-115. https://doi.org/10.1016/j.bbr.2003.08.024.

Astur, R. S., Tropp, J., Sava, S., Constable, R. T., \& Markus, E. J. (2004). Sex differences and correlations in a virtual Morris water task, a virtual radial arm maze, and mental rotation. Behavioural Brain Research, 151(1-2), 103-115.

https://doi.org/10.1016/j.bbr.2003.08.024.

Astur, R. S., Tropp, J., Sava, S., Constable, R. T., \& Markus, E. J. (2004). Sex differences and correlations in a virtual Morris water task, a virtual radial arm maze, and mental rotation. Behavioural Brain Research, 151(1-2), 103-115. https://doi.org/10.1016/j.bbr.2003.08.024.

Ayaz, H., Allen, S. L., Platek, S. M., \& Onaral, B. (2008). Maze Suite 1.0: a complete set of tools to prepare, present, and analyze navigational and spatial cognitive neuroscience experiments. Behavior Research Methods, 40(1), 353-359. https://doi.org/10.3758/BRM.40.1.353. 
Baenninger, M., \& Newcombe, N. (1989). The role of experience in spatial test performance: A meta-analysis. Sex Roles, 20(5-6), 327-344. https://doi.org/10.1007/BF00287729.

Bakker, N. H., Werkhoven, P. J., \& Passenier, P. O. (1999). The effects of proprioceptive and visual feedback on geographical orientation in virtual environments. Presence, 8(1), 3653. https://doi.org/10.1162/105474699566035.

Berg, K., Wood-Dauphinee, S., Williams, J. I., \& Gayton, D. (1989). Measuring balance in the elderly: Preliminary development of an instrument. Physiotherapy Canada, 41(6), 304311. https://doi.org/10.3138/ptc.41.6.304.

Berg, K., Wood-Dauphinee, S., \& Williams, J. I. (1995). The Balance Scale: reliability assessment with elderly residents and patients with an acute stroke. Scandinavian journal of rehabilitation medicine, 27(1), 27-36.

Bernier, J. N., \& Perrin, D. H. (1998). Effect of coordination training on proprioception of the functionally unstable ankle. The Journal of Orthopaedic and Sports Physical Therapy, 27(4), 264-275. https://doi.org/10.2519/jospt.1998.27.4.264.

Berthoz A. (1996) "How does the cerebral cortex process and utilize vestibular signals?" in Disorders of the Vestibular System, eds Baloh R., Halmagyi G. M., editors. (New YorkOxford: Oxford University Press; ), 113-125.

Berthoz, A., \& Viaud-Delmon, I. (1999). Multisensory integration in spatial orientation. Current opinion in neurobiology, 9(6), 708-712.

Bigelow, R. T., \& Agrawal, Y. (2015). Vestibular involvement in cognition: Visuospatial ability, attention, executive function, and memory. Journal of Vestibular Research: Equilibrium and Orientation, 25(2), 73-89. https://doi.org/10.3233/VES-150544

Burgess, N., Maguire, E. A., \& O’Keefe, J. (2002, August 15). The human hippocampus and spatial and episodic memory. Neuron. https://doi.org/10.1016/S0896-6273(02)00830-9. 
Calvert, G., Spence, C., \& Stein, B. E. (2004). The handbook of multisensory processes. The Handbook of Multisensory Processes, 933. https://doi.org/nicht verfügbar?

Castel, A. D., Pratt, J., \& Drummond, E. (2005). The effects of action video game experience on the time course of inhibition of return and the efficiency of visual search. Acta Psychologica, 119(2), 217-230. https://doi.org/10.1016/j.actpsy.2005.02.004.

Chance, S. S., Gaunet, F., Beall, A. C., \& Loomis, J. M. (1998). Locomotion Mode Affects the Updating of Objects Encountered During Travel: The Contribution of Vestibular and Proprioceptive Inputs to Path Integration. Presence: Teleoperators and Virtual Environments, 7(2), 168-178. https://doi.org/10.1162/105474698565659.

Chance, S. S., Gaunet, F., Beall, A. C., \& Loomis, J. M. (1998). Locomotion Mode Affects the Updating of Objects Encountered During Travel: The Contribution of Vestibular and Proprioceptive Inputs to Path Integration. Presence: Teleoperators and Virtual Environments, 7(2), 168-178. https://doi.org/10.1162/105474698565659.

Coluccia, E., \& Louse, G. (2004). Gender differences in spatial orientation: A review. Journal of Environmental Psychology. https://doi.org/10.1016/j.jenvp.2004.08.006.

Cornwell, B. R., Johnson, L. L., Holroyd, T., Carver, F. W., \& Grillon, C. (2008). Human Hippocampal and Parahippocampal Theta during Goal-Directed Spatial Navigation Predicts Performance on a Virtual Morris Water Maze. Journal of Neuroscience, 28(23), 5983-5990. https://doi.org/10.1523/JNEUROSCI.5001-07.2008.

Dabbs, J. M., Chang, E.-L., Strong, R. A., \& Milun, R. (1998). Spatial Ability, Navigation Strategy, and Geographic Knowledge Among Men and Women. Evolution and Human Behavior, 19(2), 89-98. https://doi.org/10.1016/S1090-5138(97)00107-4.

Darken, R. P., \& Sibert, J. L. (1996). Navigating large virtual spaces. International Journal of Human-Computer Interaction, 8(1), 49-71. https://doi.org/10.1080/10447319609526140. 
De Fiebre, N. C., Sumien, N., Forster, M. J., \& De Fiebre, C. M. (2006). Spatial learning and psychomotor performance of C57BL/6 mice: Age sensitivity and reliability of individual differences. Age, 28(3), 235-253. https://doi.org/10.1007/s11357-006-9027-3.

Diracoglu, D., Aydin, R., Baskent, A., \& Celik, A. (2005). Effects of Kinesthesia and Balance Exercises in Knee Osteoarthritis. JCR: Journal of Clinical Rheumatology, 11(6), 303-310. https://doi.org/10.1097/01.rhu.0000191213.37853.3d.

Driscoll, I., Hamilton, D. A., Yeo, R. A., Brooks, W. M., \& Sutherland, R. J. (2005). Virtual navigation in humans: The impact of age, sex, and hormones on place learning. Hormones and Behavior, 47(3), 326-335. https://doi.org/10.1016/j.yhbeh.2004.11.013.

Eils, E., \& Rosenbaum, D. (2001). A multi-station proprioceptive exercise program in patients with ankle instability. Medicine \& Science in Sports \& Exercise, 33(12), 1991-1998 https://doi.org/10.1097/00005768-200112000-00003.

Etienne, A. S., \& Jeffery, K. J. (2004). Path integration in mammals. Hippocampus. https://doi.org/10.1002/hipo.10173.

Etienne, A. S., Teroni, E., Maurer, R., Portenier, V., \& Saucy, F. (1985). Short-distance homing in a small mammal: the role of exteroceptive cues and path integration. Experientia, 41(1), 122-125. https://doi.org/10.1007/BF02005909.

Feng, J., Spence, I., \& Pratt, J. (2007). Playing an action video game reduces gender differences in spatial cognition. Psychological science, 18(10), 850-855.

Fusco, Andrea \& Giancotti, Giuseppe \& Foster, Carl \& Varalda, Carlo \& Capranica, Laura \& Cortis, Cristina. (2018). Effect of Visual Biofeedback On Wobble Board Balance Performance in Relation to Gender. J Curr Res Sports. 2017; 1(1): 1002

Fraizer, E. V., \& Mitra, S. (2008). Methodological and interpretive issues in posture-cognition dual-tasking in upright stance. Gait \& posture, 27(2), 271-279. 
Filimon, F. (2015). Are All Spatial Reference Frames Egocentric? Reinterpreting Evidence for Allocentric, Object-Centered, or World-Centered Reference Frames. Frontiers in Human Neuroscience, 9. https://doi.org/10.3389/fnhum.2015.00648.

Gale, N., Golledge, R. G., Pellegrino, J. W., \& Doherty, S. (1990). The acquisition and integration of route knowledge in an unfamiliar neighborhood. Journal of Environmental Psychology, 10(1), 3-25. https://doi.org/10.1016/S0272-4944(05)80021-0.

Galea, L. A. M., \& Kimura, D. (1993). Sex differences in route-learning. Personality and Individual Differences, 14(1), 53-65. https://doi.org/10.1016/0191-8869(93)90174-2.

Galea, L. A. M., \& Kimura, D. (1993). Sex differences in route-learning. Personality and Individual Differences, 14(1), 53-65. https://doi.org/10.1016/0191-8869(93)90174-2.

Gauffin, H., Tropp, H., \& Odenrick, P. (1988). Effect of ankle disk training on postural control in patients with functional instability of the ankle joint. International Journal of Sports Medicine, 9(2), 141-4. https://doi.org/10.1055/s-2007-1024996.

Goodrich-Hunsaker, N. J., Livingstone, S. A., Skelton, R. W., \& Hopkins, R. O. (2010). Spatial deficits in a virtual water maze in amnesic participants with hippocampal damage. Hippocampus, 20(4), 481-491. https://doi.org/10.1002/hipo.20651.

Green, C. S., \& Bavelier, D. (2003). Action video game modifies visual selective attention. Nature, 423(6939), 534-537. https://doi.org/10.1038/nature01647.

Green, C. S., \& Bavelier, D. (2006). Effect of action video games on the spatial distribution of visuospatial attention. Journal of Experimental Psychology: Human Perception and Performance, 32(6), 1465-1478. https://doi.org/10.1037/0096-1523.32.6.1465.

Green, C. S., \& Bavelier, D. (2007). Action-video-game experience alters the spatial resolution of vision: Research article. Psychological Science, 18(1), 88-94. https://doi.org/10.1111/j.1467-9280.2007.01853.x. 
Grön, G., Wunderlich, a P., Spitzer, M., Tomczak, R., \& Riepe, M. W. (2000). Brain activation during human navigation: gender-different neural networks as substrate of performance. Nature Neuroscience, 3(4), 404-8. https://doi.org/10.1038/73980.

Hamilton, D. A., Driscoll, I., \& Sutherland, R. J. (2002). Human place learning in a virtual Morris water task: Some important constraints on the flexibility of place navigation. Behavioural Brain Research, 129(1-2), 159-170. https://doi.org/10.1016/S0166-4328(01)00343-6.

Hanggi J, Koeneke S, Bezzola L, Jancke L (2010) Structural neuroplasticity in the sensorimotor network of professional female ballet dancers. Human Brain Mapping 31: 1196-1206.

Hanlon, F. M., Weisend, M. P., Hamilton, D. A., Jones, A. P., Thoma, R. J., Huang, M., ...

Cañive, J. M. (2006). Impairment on the hippocampal-dependent virtual Morris water task in schizophrenia. Schizophrenia Research, 87(1-3), 67-80.

https://doi.org/10.1016/j.schres.2006.05.021.

Horn KM, DeWitt JR, Nielson H.C.(1981). Behavioral assessment of sodium arsanilate induced vestibular dysfunction in rats. Physiol Psychol 9:371-378.

Hummel, N., Hüfner, K., Stephan, T., Linn, J., Kremmyda, O., Brandt, T., \& Flanagin, V. L. (2014). Vestibular loss and balance training cause similar changes in human cerebral white matter fractional anisotropy. PloS one, 9(4), e95666.

Hüfner, K., Binetti, C., Hamilton, D. A., Stephan, T., Flanagin, V. L., Linn, J., ... \& Strupp, M. (2011). Structural and functional plasticity of the hippocampal formation in professional dancers and slackliners. Hippocampus, 21(8), 855-865.

Jacobs, W. J., Laurance, H. E., \& Thomas, K. G.-F. (1997). Place learning in virtual space I: Acquisition, overshadowing, and transfer. Learning and Motivation, Vol 28(4), 521-541. https://doi.org/10.1006/lmot.1997.0977. 
Jacobs, W. J., Laurance, H. E., \& Thomas, K. G.-F. (1997). Place learning in virtual space I: Acquisition, overshadowing, and transfer. Learning and Motivation, Vol 28(4), 521-541. https://doi.org/10.1006/lmot.1997.0977.

Jansen-Osmann, P., \& Wiedenbauer, G. (2004). The representation of landmarks and routes in children and adults: A study in a virtual environment. Journal of Environmental Psychology, 24(3), 347-357. https://doi.org/10.1016/j.jenvp.2004.08.003.

Kerr, B., Condon, S. M., \& McDonald, L. A. (1985). Cognitive spatial processing and the regulation of posture. Journal of Experimental Psychology: Human Perception and Performance, 11(5), 617-622.

Kidgell, D. J., Horvath, D. M., Jackson, B. M., \& Seymour, P. J. (2007). Effect of six weeks of dura disc and mini-trampoline balance training on postural sway in athletes with functional ankle instability. Journal of Strength and Conditioning Research, 21(2), 466.

Lackner, J. R., \& DiZio, P. (2005). Vestibular, proprioceptive, and haptic contributions to spatial orientation. Annu. Rev. Psychol., 56, 115-147.

Law, D. J., Pellegrino, J. W., \& Hunt, E. B. (1993). COMPARING THE TORTOISE AND THE HARE: Gender Differences and Experience in Dynamic Spatial Reasoning Tasks. Psychological Science, 4(1), 35-40. https://doi.org/10.1111/j.1467-9280.1993.tb00553.x.

Levy, L. J., Astur, R. S., \& Frick, K. M. (2005). Men and Women Differ in Object Memory but Not Performance of a Virtual Radial Maze. Behavioral Neuroscience, 119(4), 853-862. https://doi.org/10.1037/0735-7044.119.4.853.

Lindner, M. D. (1997). Reliability, distribution, and validity of age-related cognitive deficits in the Morris water maze. Neurobiology of Learning and Memory, 68(3), 203-20. https://doi.org/10.1006/nlme.1997.3782. 
Loomis, J. M., Klatzky, R. L., Golledge, R. G., \& Philbeck, J. W. (1999). Human navigation by path integration. In R. G. Golledge (Ed.), Wayfinding Behavior: Cognitive Mapping and Other Satial Processes (pp. 125-151). Johns Hopkins University Press.

Marois, R., \& Ivanoff, J. (2005). Capacity limits of information processing in the brain. Trends in cognitive sciences, 9(6), 296-305

Maylor, E. A., Allison, S., \& Wing, A. M. (2001). Effects of spatial and nonspatial cognitive activity on postural stability. British Journal of Psychology, 92(2), 319-338.

McClurg, P. A., \& Chaille, C. (1987). Computer games: Environments for Developing Spatial Cognition? Journal of Educational Computing Research, 3(1), 95-112. https://doi.org/10.1017/CBO9781107415324.004.

McNaughton, B. L., Barnes, C. a, Gerrard, J. L., Gothard, K., Jung, M. W., Knierim, J. J., ... Weaver, K. L. (1996). Deciphering the hippocampal polyglot: the hippocampus as a path integration system. The Journal of Experimental Biology, 199(Pt 1), 173-185.

McNaughton, B. L., Battaglia, F. P., Jensen, O., Moser, E. I., \& Moser, M. B. (2006). Path integration and the neural basis of the'cognitive map'. Nature Reviews Neuroscience, 7(8), 663-678.

Miller, S., Potegal, M., \& Abraham, L. (1983). Vestibular involvement in a passive transport and return task. Physiological Psychology, 11(1), 1-10. https://doi.org/10.3758/BF03326763.

Mittelstaedt, M. L., \& Mittelstaedt, H. (1980). Homing by path integration in a mammal. Naturwissenschaften, 67(11), 566-567. https://doi.org/10.1007/BF00450672.

Moffat, S. D., Hampson, E., \& Hatzipantelis, M. (1998). Navigation in a "Virtual” Maze: Sex Differences and Correlation With Psychometric Measures of Spatial Ability in Humans. Evolution and Human Behavior, 19(519), 73-87. https://doi.org/10.1016/S1090$\underline{5138(97) 00104-9 .}$. 
Montello, D. R., Lovelace, K. L., Golledge, R. G., \& Self, C. M. (1999). Sex-Related Differences and Similarities in Geographic and Environmental Spatial Abilities. Annals of the Association of American Geographers, 89(3), 515-534. https://doi.org/10.1111/0004$\underline{5608.00160 .}$.

Morris, R. G. M. (1981). Spatial localization does not require the presence of local cues. Learning and Motivation, 12(2), 239-260. https://doi.org/10.1016/0023-9690(81)90020-5.

Morris, R. G. M., Garrud, P., Rawlins, J. N. P., \& O’Keefe, J. (1982). Place navigation impaired in rats with hippocampal lesions. Nature, 297(5868), 681-683. https://doi.org/10.1038/297681a0.

Mueller, S. C., Jackson, C. P. T., \& Skelton, R. W. (2008). Sex differences in a virtual water maze: An eye tracking and pupillometry study. Behavioural Brain Research, 193(2), 209215. https://doi.org/10.1016/j.bbr.2008.05.017.

Nagahara, A. H., Otto, T., \& Gallagher, M. (1995). Entorhinal-perirhinal lesions impair performance of rats on two versions of place learning in the Morris water maze. Behavioral Neuroscience, 109(1), 3-9. https://doi.org/10.1037//0735-7044.109.1.3.

O’Laughlin, E. M., \& Brubaker, B. S. (1998). Use of landmarks in cognitive mapping: Gender differences in self report versus performance. Personality and Individual Differences, 24(97), 595-601. https://doi.org/10.1016/S0191-8869(97)00237-7.

Persson, J., Herlitz, A., Engman, J., Morell, A., Sjölie, D., Wikström, J., \& Söderlund, H. (2013). Remembering our origin: Gender differences in spatial memory are reflected in gender differences in hippocampal lateralization. Behavioural Brain Research, 256, 219-228. https://doi.org/10.1016/j.bbr.2013.07.050.

Pfeiffer, C., Serino, A., \& Blanke, O. (2014). The vestibular system: a spatial reference for bodily self-consciousness. Frontiers in Integrative Neuroscience, 8. https://doi.org/10.3389/fnint.2014.00031 
Potegal M. (1982). Vestibular and neostriatal contributions to spatial orientation, in Spatial Abilities: Development and Physiological Foundation (pp.361-387) ed Potegal M., editor. (New York, NY: Academic Press)

Potegal, M., Day, M. J., \& Abraham, L. (1977). Maze-orientation, visual and vestibular cues in two-maze spontaneous alternation of rats. Physiological Psychology. US: Psychonomic Society. https://doi.org/10.3758/BF03337846.

Rieser, J. J., Guth, D. A., \& Hill, E. W. (1986). Sensitivity to perspective structure while walking without vision. Perception, 15(2), 173-188. https://doi.org/10.1068/p150173.

Rogge, A. K., Röder, B., Zech, A., Nagel, V., Hollander, K., Braumann, K. M., \& Hötting, K. (2017). Balance training improves memory and spatial cognition in healthy adults. Scientific reports, $7(1), 5661$.

Rossano, M. J., \& Moak, J. (1998). Spatial representations acquired from computer models : Cognitive load, orientation specificity and the acquisition of survey knowledge. British Journal of Psychology, 89, 481-497.

Sandstrom, N. J., Kaufman, J., \& A. Huettel, S. (1998). Males and females use different distal cues in a virtual environment navigation task. Cognitive Brain Research, 6(4), 351-360. https://doi.org/10.1016/S0926-6410(98)00002-0.

Sandstrom, N. J., Kaufman, J., \& A. Huettel, S. (1998). Males and females use different distal cues in a virtual environment navigation task. Cognitive Brain Research, 6(4), 351-360. https://doi.org/10.1016/S0926-6410(98)00002-0.

Saucier, D. M., Green, S. M., Leason, J., MacFadden, A., Bell, S., \& Elias, L. J. (2002). Are sex differences in navigation caused by sexually dimorphic strategies or by differences in the ability to use the strategies? Behavioral Neuroscience, 116(3), 403-410. https://doi.org/10.1037//0735-7044.116.3.403. 
Schmitz, S. (1997). Gender-Related Strategies in Environmental Development: Effects of Anxiety on Wayfinding in and Representation of a Three-Dimensional Maze. Journal of Environmental Psychology, 17(3), 215-228. https://doi.org/http://dx.doi.org/10.1006/jevp.1997.0056.

Sugiura, H., Takeda, S., Araki, F., Nobukawa. S. (2017) Reliability and Sex Differences in a Balance Board Test on an Unstable Stool in the Elderly. American Journal of Sports Science and Medicine. Vol. 5, No. 1, pp 11-14.

Silsupadol, P., Siu, K. C., Shumway-Cook, A., \& Woollacott, M. H. (2006). Training of balance under single-and dual-task conditions in older adults with balance impairment. Physical therapy, 86(2), 269-281.

Smith, D. H., Okiyama, K., Thomas, M. J., Claussen, B., \& McIntosh, T. K. (1991). Evaluation of memory dysfunction following experimental brain injury using the Morris water maze. Journal of Neurotrauma, 8(4), 259-269. https://doi.org/10.1089/neu.1991.8.259.

Shumway-Cook, A., \& Woollacott, M. (2000). Attentional demands and postural control: the effect of sensory context. Journals of Gerontology Series A: Biological and Medical Sciences, 55(1), 10.

Shumway-Cook, A., Woollacott, M., Kerns, K. A., \& Baldwin, M. (1997). The effects of two types of cognitive tasks on postural stability in older adults with and without a history of falls. The Journals of Gerontology Series A: Biological Sciences and Medical Sciences, 52(4), M232-M240.

Swan, L., Otani, H., Loubert, P. V., Sheffert, S. M., \& Dunbar, G. L. (2004). Improving balance by performing a secondary cognitive task. British Journal of Psychology, 95(1), 31-40.

Tombu, M., \& Jolicœur, P. (2003). A central capacity sharing model of dual-task performance. Journal of Experimental Psychology: Human Perception and Performance, 29(1), 3. 
Tlauka, M., Brolese, A., Pomeroy, D., \& Hobbs, W. (2005). Gender differences in spatial knowledge acquired through simulated exploration of a virtual shopping centre. Journal of Environmental Psychology, 25(1), 111-118. https://doi.org/10.1016/j.jenvp.2004.12.002.

Waddington, G. S., \& Adams, R. D. (2004). The Effect of a 5-Week Wobble-Board Exercise Intervention on Ability to Discriminate Different Degrees of Ankle Inversion, Barefoot and Wearing Shoes: A Study in Healthy Elderly. Journal of the American Geriatrics Society, 52(4), 573-576. https://doi.org/10.1111/j.1532-5415.2004.52164.x.

Waller, D. (2000). Individual differences in spatial learning from computer-simulated environments. Journal of Experimental Psychology: Applied, 6(4), 307-321. https://doi.org/10.1037//1076-898X.6.4.307.

Waller, D., Knapp, D., \& Hunt, E. (2001). Spatial representations of virtual mazes: the role of visual fidelity and individual differences. Human Factors, 43(1), 147-158. https://doi.org/10.1518/001872001775992561.

Waller, D., Loomis, J. M., \& Steck, S. D. (2003). Inertial cues do not enhance knowledge of environmental layout. Psychonomic Bulletin \& Review, 10(4), 987-993. https://doi.org/10.3758/BF03196563.

Waller, L., Haunjürgens, Boß, \& Becker. (2004). Body-based senses enhance knowledge of directions in large-scale environments. Psychonomic Bulletin \& Review, 11(1), 157-163. https://doi.org/10.3758/BF03206476.

Wiener S. I., Berthoz A. (1993). Forebrain structures mediating the vestibular contribution during navigation. In Multisensory Control of Movement, ed. Berthoz A., editor. (Oxford: Oxford University Press).

Wilson, P. N., Foreman, N., \& Tlauka, M. (1997). Transfer of spatial information from a virtual to a real environment. Human Factors, 39, 526-531. 
Williams, J., \& Bentman, S. (2014). An investigation into the reliability and variability of wobble board performance in a healthy population using the SMARTwobble instrumented wobble board. Physical Therapy in Sport, 15(3), 143-147.

Wraga, M., Thompson, W. L., Alpert, N. M., \& Kosslyn, S. M. (2003). Implicit transfer of motor strategies in mental rotation. Brain and Cognition, 52(2), 135-143.

https://doi.org/10.1016/S0278-2626(03)00033-2. 